Journal of Social Sciences 5 (4): 466-470, 2009

ISSN 1549-3652

(C) 2009 Science Publications

\title{
Causal Factors Influencing Adversity Quotient of Twelfth Grade and Third-Year Vocational Students
}

\author{
${ }^{1}$ Rachapoom Pangma, ${ }^{2}$ Sombat Tayraukham and ${ }^{3}$ Prasart Nuangchalerm \\ ${ }^{1}$ Lalomwittaya School, Phusingh District, Sisaket Province, 33140 Thailand \\ ${ }^{2}$ Department of Educational Research and Development, Faculty of Education, Mahasarakham \\ University, Mahasarakham 44000, Thailand \\ ${ }^{3}$ Department of Curriculum and Instruction, Faculty of Education, Mahasarakham University, \\ Mahasarakham 44000 Thailand
}

\begin{abstract}
Problem statement: The aim of this research was to study the causal factors influencing students' adversity between twelfth grade and third-year vocational students in Sisaket province, Thailand. Six hundred and seventy two of twelfth grade and 376 third-year vocational students were selected by multi-stage random sampling techniques. Approach: The instruments used for collecting data were: A scale on self-esteem, a scale on dominance, a scale on self-confidence, a scale on sense of personal freedom, a scale on achievement motivation, a scale on ambition, a scale on enthusiasm, a scale on responsibility, a scale on future orientation, and an adversity quotient scale. The data were analyzed by validity test of the causal relationship model. Results: The results of the study were as follows: (1) variables influencing the adversity quotient of 12th grade and third-year vocational students were dominance, sense of personal freedom, self-esteem, enthusiasm, self-confidence, ambition and achievement motivation. (2) Variables are directly influencing the adversity quotient of twelfth grade students was self-confidence while the variables both directly and indirectly influencing the adversity quotient of students were dominance, sense of personal freedom, selfesteem, and enthusiasm. (3) Variable are directly influencing adversity quotient of third-year vocational students was achievement motivation, the variables are indirectly influencing the adversity quotient of these students was dominance while the variables both directly and indirectly influencing the adversity quotient of these students were sense of personal freedom, self-esteem, enthusiasm, self-confidence, and ambition. Conclusion: In conclusion, the results of this study could be used as beneficial information for parents, teachers and those involved in education for developing students to have adversity quotient as well as to be used as guidelines for providing education in the future.
\end{abstract}

Key words: Adversity quotient, causal factors influencing, vocational student, twelfth grade, Thailand

\section{INTRODUCTION}

Confrontation solving and fighting against the adversity are very important for human being's life because human will have a happy life or not depends on how well he can solve and fight against the problems which they are facing ${ }^{[1]}$. Nowadays, there is the theory called Adversity Quotient (AQ) developed by Stoltz ${ }^{[2]}$, is a reflection of the one who is facing a problem. The type of the response is called the simple adversity quotient cooperated with Emotional Quotient (EQ). This response sometimes happens automatically. He revealed that when analyzing the person who was successful in his life by testing his intellect, we didn't find any thing presenting the success of him but what was found about his adversity quotient. Any one who can confront and fight against the problem wisely will be successful. This is especially true in our today world; people are to adapt themselves in relation to busy life. They have to manage their life or even other people lives to avoid facing a problem as well as possible, or if it happens, they are to solve the problem in wisely ${ }^{[3]}$.

Adversity quotient begins its first by cognitive development. Teenagers will learn how to response to the questions and solve problems or even learn to have no response to some problems. These experiences of children have been developed with them since they were born which can be improved or developed; therefore, the parents propose a good a good care so that they will grow up with efficiency.

Twelfth grade and 3rd year vocational students are youth. During this age, their emotion is quick-tempered, they will be stressful; on the other hand, they are ready to search and develop their ego identity which is a basic

Corresponding Author: Sombat Tayraukham, Faculty of Education, Mahasarakham University, Mahasarakham 44000 Thailand 
development of personality. Any youth that can adapt himself to fit the surrounding environment. They will have not only a good physical health but a mental one as well. Nevertheless, if the teenagers cannot adjust themselves, they will be stressful and then they will properly make mistakes at the result.

As today, there are a lot of problems such as drug addiction, sex assembling and suicide. Due to these, the teenagers themselves cannot control their emotion when they face the serious situation; hence, they try to escape by doing such wrong things ${ }^{[4]}$ and the important thing is that they lack of an adversity quotient. Therefore, the schools and also the college should play an important role to manage and provide the students' activities that can help them gain more adversity quotient ${ }^{[5,6]}$. The researcher is also interested in the factors that influencing the student' adversity quotient.

\section{MATERIALS AND METHODS}

Objectives of the research: This research aimed to study the factors influence variables that affect the adversity quotient of twelfth grade and third-year vocational students, to develop the casual model factors that influence on the confrontation and fighting against the problems of twelfth grade and third-year vocational students.

The research hypothesis: The researchers had studied the documents and related research. Therefore, the hypothesizes of this research were: ambition, responsibility, future expectation will take a direct effect on students' adversity quotient and the factors such influential needs, self-esteem, self confidence, self independence, enthusiasm and incentive will influence on both direct and indirect ways to twelfth grade and 3rd year vocational students' adversity quotient.

The research regulations: This research was a multirelation one. The details of the research processes were as follows.

The populations of this research were the students from twelfth grade and third-year vocational in Sisaket province. The samples comprised of 1,048 students attending twelfth grade and third-year vocational students in Sisaket province. They were selected by multi-stage random sampling.

The tools employed in this research comprised of two evaluation questionnaires including 9-factor influencing on students' adversity quotient which had discriminant power was 0.68-0.92. Reliability of students' adversity quotient questionnaire was 0.94 .

In terms of data collection, the researchers collected information from samples by giving the evaluation forms to the sample; twelfth grade and thirdyear vocational students.
There were three parts of data analysis including; (1) analyze the basic statistics to know both samplers' characteristic and explications of the variables, mean, standard deviation; (2) analyze the relationship between the variables by Pearson product moment correlation coefficient; (3) check the correlation of casual factor models according to the research hypothesis and empirical data by PAQ model.

\section{RESULTS}

The results on analysis of casual factors that influenced on twelfth grade students' adversity quotient were shown in the Fig. 1.

The results on analysis the correlations of variable models, hypothesis models and adjusted models based on PAQ analysis method were shown in the Table 1.

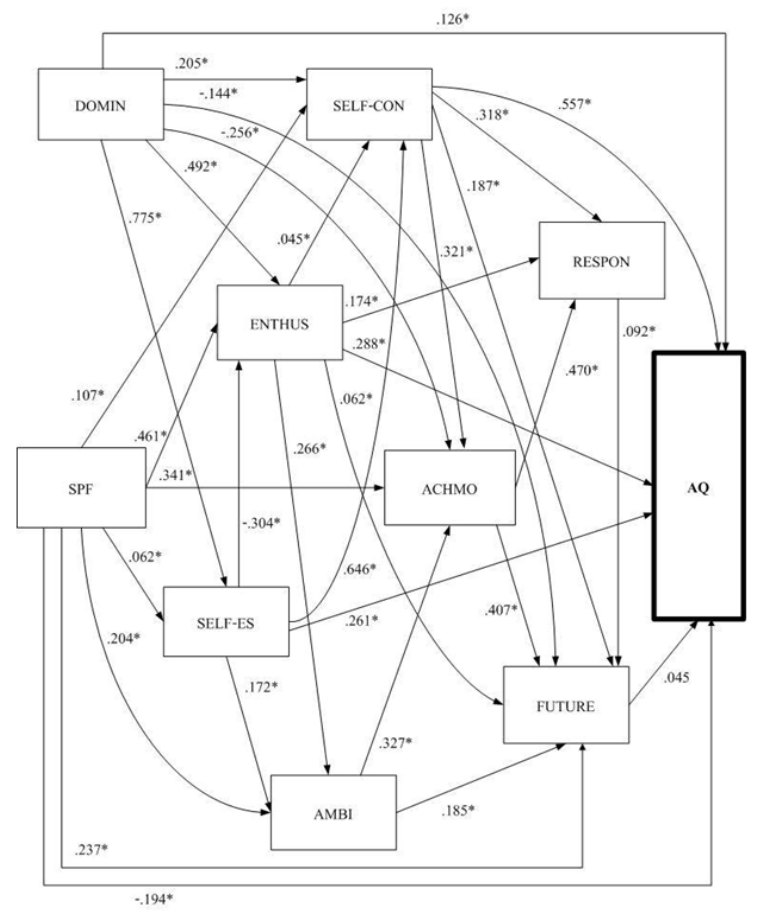

Fig. 1: Variable model that influence on twelfth grade students' adversity quotient

Table 1: The relationship of complete variables influencing on twelfth grade students' adversity quotient by PAQ

\begin{tabular}{|c|c|c|c|c|c|}
\hline Models & $\mathrm{R}_{\mathrm{m}}^{2}$ & M & Q & W & $\begin{array}{l}\text { Conclusions } \\
\text { and evident } \\
\text { data }\end{array}$ \\
\hline Complete variables & 0.999 & - & - & & - \\
\hline Hypothesis variables & - & 0.9924 & 0.12 & $138.710^{*}$ & Uncorrelated \\
\hline Adjusted models & - & 0.9990 & 0.98 & 13.022 & Correlated \\
\hline
\end{tabular}


According to the statistical value from the complete model, $\mathrm{R}_{\mathrm{m}}^{2}, \mathrm{M}$, indicated that the variable (Fig. 1) presented the casual relationship could explain the whole relationship system at $99.90 \%$ while the hypothesis variables could explain it as $99.24 \%$ and the improved variables could also explain the factor at $99.90 \%$.

When comparing the statistical relationship of $\mathrm{Q}$ and $\mathrm{W}$, we found out that the hypothesis variable models could explain the whole relationship system differently from the complete variables but the adjusted variables and the complete ones had no difference in explanation. This meant that hypothesis model was not related to the empirical data, while the adjusted variables were related to it.

The casual factor coefficients from calculating in terms of direct, indirect, and total effects influencing the students' Adversity Quotient, (AQ, improved by PAQ Analysis) were shown in Table 2.

Table 2: Direct, indirect and total effects and multi-relation variable model coefficient that influenced on twelfth grade students' adversity quotient

\begin{tabular}{llrrr}
\hline Variables & $\begin{array}{l}\text { Multi-relation } \\
\text { coefficient }\end{array}$ & $\begin{array}{c}\text { Direct } \\
\text { effect }\end{array}$ & $\begin{array}{c}\text { Indirect } \\
\text { effect }\end{array}$ & $\begin{array}{r}\text { Total } \\
\text { effect }\end{array}$ \\
\hline DOMIN & 0.400 & 0.126 & 0.174 & 0.300 \\
SPF & 0.411 & -0.194 & -0.057 & -0.251 \\
SELF-ES & 0.409 & 0.268 & 0.447 & 0.715 \\
ENTHUS & 0.474 & 0.288 & 0.025 & 0.313 \\
SELF-C0N & 0.472 & 0.557 & - & 0.557 \\
\hline
\end{tabular}

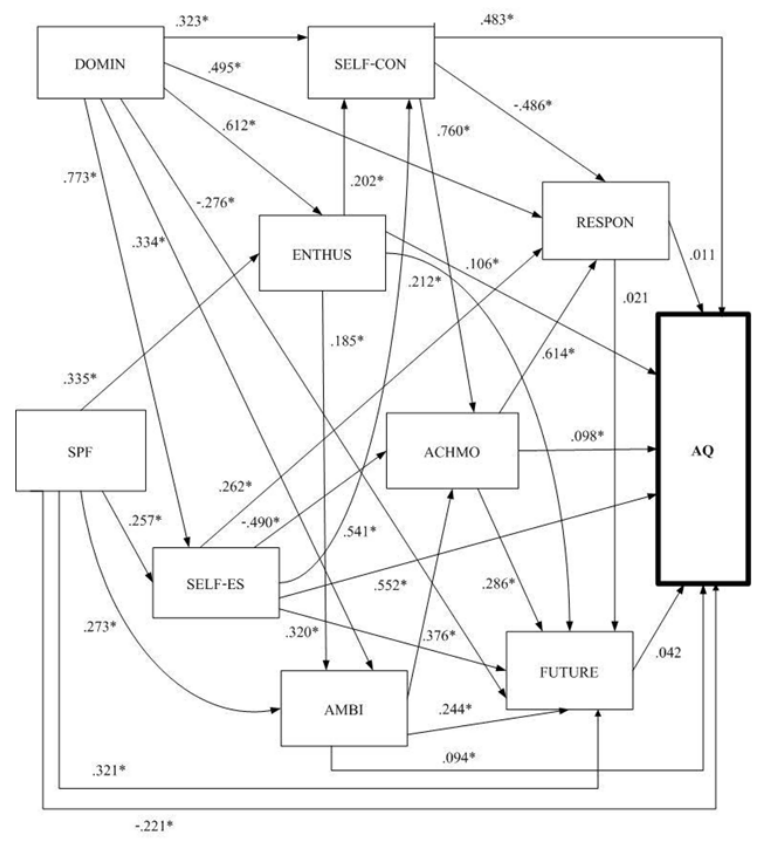

Fig. 2: Casual factor model that influenced on lower three vocational students' adversity quotient
According to Table 2, the most effective variable was the student's self-esteem (SELF-ES). The variable influenced only in direct way was the self-confidence, while the dominance variable (DOMIN), self-personal free, self-esteem an enthusiasm took both direct and indirect effects.

The correlation analysis of casual factor model that influenced on lower three vocational students' adversity quotient were shown in Fig. 2. The hypothesis variable and improved variable models by using PAQ analytical method were shown as in Table 3.

As the empirical data shown in Table 3, when comparing $\mathrm{R}_{\mathrm{m}}{ }_{\mathrm{m}}$, $\mathrm{M}$ statistical value from the complete model, you will know that the value that appeared on figure 2, a casual correlation could explain the relationship at $99.87 \%$ While hypothesis and adjusted models could explain at 98.31 and 99.86 in respectively. If considering the correlative statistic value of $\mathrm{Q}$ and $\mathrm{W}$, you will find out that the hypothesis model could be differently explained the whole relationship from the complete model. On the other hands, developed model was not differ from completed model in terms of correlation explanation. Therefore, the hypothesis variable was not correlated to the empirical data.

The coefficient values from calculating could find out the direct, indirect and total effects on students' Adversity Quotient (AQ) that was developed by PAQ analytical model were shown in Table 4.

The data from Table 4 indicated that the most influential variable was self-esteem (SELF-ES).

Table 3: The correlative statistical values on complete variable, hypothesis variable and improved variable models that had been analyzed analytical method

\begin{tabular}{llllll}
\hline Models & $\mathrm{R}_{\mathrm{m}}^{2}$ & $\mathrm{M}$ & $\mathrm{Q}$ & $\mathrm{W}$ & $\begin{array}{c}\text { Correlated } \\
\text { empirical data }\end{array}$ \\
\hline Complete model & 0.9987 & - & - & & - \\
Hypothesis model & - & 0.9831 & 0.077 & $914.480 *$ & Unrelated \\
Improved model & - & 0.9986 & 0.987 & 4.595 & Related \\
\hline
\end{tabular}

Table 4: Direct, indirect and total effects and and multi-relation variable model coefficient that influenced on third-year vocational students' adversity quotient

\begin{tabular}{lcccr}
\hline Variables & \multicolumn{2}{l}{$\begin{array}{l}\text { Multi-relation Direct } \\
\text { coefficient }\end{array}$} & $\begin{array}{l}\text { Indirect } \\
\text { effect }\end{array}$ & $\begin{array}{r}\text { Total } \\
\text { effect }\end{array}$ \\
\hline DOMIN & 0.653 & - & 0.486 & 0.486 \\
SPF & -0.044 & -0.221 & 0.081 & -0.140 \\
SELF-ES & 0.780 & 0.552 & 0.231 & 0.783 \\
ENTHUS & 0.090 & 0.106 & 0.080 & 0.186 \\
SELF-CON & 0.726 & 0.438 & 0.074 & 0.512 \\
AMBI & 0.103 & 0.094 & 0.037 & 0.131 \\
ACHMO & 0.152 & 0.098 & - & 0.098 \\
\hline
\end{tabular}


The variable that had only direct effect was an achievement motivation (ACHMO). The variables indirectly influencing the adversity quotient of these students was dominance (DOMIN) while the variables both directly and indirectly influencing the adversity quotient of them were sense of personal freedom (SPF), self-esteem (SELF-ES), enthusiasm (ENTHUS), selfconfidence (SELF-CON), and ambition (AMBI).

\section{DISCUSSION}

The variable that influenced on only in direct way of twelfth grade students' adversity quotient was the self-confidence, while the dominance variable (DOMIN), self-personal freedom (SPF), self-esteem (SELF-ES) and enthusiasm (ENTHUS) took both direct and indirect effects. In case of third-year vocational students, the variable that had only direct effect to them was an achievement motivation (ACHMO). The variables indirectly influencing the adversity quotient of these students was dominance (DOMIN) while the variables both directly and indirectly influencing the adversity quotient of them were sense of personal freedom (SPF), self-esteem (SELF-ES), enthusiasm (ENTHUS), self-confidence (SELF-CON) and ambition (AMBI). The discussions of these were as follows:

- Dominance was the variable indirectly influencing students' adversity quotient at 0.05 level of significance. The students' dominance desire was performed through their enthusiasm, selfconfidence, self-esteem and ambition because it was an inside authority that caused the behaviors. The behaviors would happen according to another person's reaction such as persuasion or force and they could directly influence on both responsibility and future expectation. Koonthaisong ${ }^{[1]}$ had studied the mental characteristic correlating with the adversity quotient abilities and revealed that the four adversity quotients including the abilities in controlling, solving, confronting problems and realizing the level of them affected the positive correlation, responsibility, expectation of future, achievement motivation, dominance, selfindependence and self-confidence

- Self-esteem was the variable influencing both direct and indirect ways to the adversity quotient at 0.05 level of significance since that person would feel pleasure of himself, he also realized that he had ability and was important for the society. Selfesteem also leaded to self-confidence, achievement motivation, responsibility and future expectation. Saenyen $^{[7]}$ indicated that the person who had high self-esteem and self-confidence was a creative person and presented as a leader. What's more, Maslow had given the meaning of the self-esteem any one was to accept not only his group but he needed to accept him as well. He was to improve and take pride of himself. It was called self-respect. If he did so, he would have a self-confidence which was not different from the hiker that he was to have an adversity quotient

- Enthusiasm variable affected both direct and indirect ways on students' adversity quotient at 0.05 level of significance. This was because the enthusiasm showed the people's carefulness. They would not postpone to work, they would be patient for any situation; moreover, the variable took an effect on ambition, self-confidence and future expectation. Untprasert ${ }^{[8]}$ revealed that enthusiasm meant the action of person to show his carefulness, strength, adversity quotient in working. The fact was that if any one was enthusiastic to work, he would be successful even if that obstacle was obviously complicated

- Self-confidence was the variable affecting both direct and indirect ways to the adversity quotient at 0.05 level of significance. He would get a success at the result. Self-confidence also directly influenced on achievement motivation and responsibility. In addition, Saenyen ${ }^{[7]}$ stated that any one who had self-esteem and self-confidence would properly had the common characteristics such as creative thinking, being a leader which were good characteristics leading to a success.

- Personal Independence affected both directly and indirectly to an adversity quotient at 0.05 level of significance but its influence was in a negative way. It meant if person who had a high personal freedom, and adversity quotient was properly decreased because they would do what they wanted without concerning with any body; nevertheless, it indirectly influenced on people's positive adversity quotient by passing through enthusiasm, selfesteem, ambition and future expectation

- Ambition was a variable influencing the adversity quotient in both direct and indirect ways because it represented a personality with a high expectation which was to be in under control for reaching the success. Ambition did influence directly on achievement motivation and future expectation as well. Khondee ${ }^{[9]}$ concluded that ambition was a desire in a secondary cell. It was the eight types of mental desire. The desire motivated that person to reach his goals 
- Achievement motivation variable is directly affected the adversity quotient since it was a kind of ambitious person. He would try with his courage to fight against everything. This took direct effect on responsibility and future expectation. The theory of McClelland on achievement motivation $^{[10,11]}$ were also related to this information. Methavee had studied the variables that influenced on the adversity quotient of level 4 students at Nongkai Province and she found that 7 variables including emotional quotient, selfconcept motivation, democratic training, dominant desire, responsibility and stress were related to the adversity quotient at 0.01 level of significance

\section{CONCLUSION}

Secondary education should consider this fact and use the research results with students so as to develop their adversity quotient. Vocational education that provide third-year vocational students should consider the research results and use them for developing the students' adversity quotient. Also, most influential variable for twelfth grade and third-year vocational students were self-esteem and self-confidence; therefore, teachers should encourage and develop students to help them by providing themselves such as making a project but it must not be so difficult than those students will think and design.

Suggestions for further study can be provided that other factors should be studied to find out whether they influence on the students' adversity quotient or not. PAL analytical model should be used instead of PAQ analytical model so as to analyze the data of correlative model because the data will be more correct. PAL model should be used as the checker to inspect nonchangeable model types from analyzing the students who have the same maturity.

\section{REFERENCES}

1. Koonthaisong, M. 2003. Some mental features that correlated to the Adversity Quotient. M.Ed. Thesis. Mahasarakham: Mahasarakham University, Thailand, unpublished document.

2. Stoltz, P.G. 1997. Adversity Quotient: Turning Obstacles into Opportunities. John Wiley and Sons, USA., ISBN: 0-4711-7892-6.

3. Baum, J.R. and E.A. Locke. 2004. The relationship of entrepreneurial traits, skill, and motivation to subsequent venture growth. J. Applied Psy., 89: 587-598.
4. Green, A. 2006. Effective personal communication skills for public relations. Creative print and design, USA. ISBN: 0-7494-4407-X.

5. Atienza, V. 2007. Towards the development of social justice. Lulu, Philipine. ISBN: 978-0-61516030-6.

6. Deb, A. and M. Arora. 2008. Resilience in children and adolescents: An overview. Psy. Stud. 53: 114-121.

7. Saenyen, R. 1997. The relationship between learning achievements and some mental social characteristics of Matthayomsuksa 2. M.Ed. Thesis. Mahasarakham: Mahasarakham University, Thailand. Unpublished document.

8. Untprasert, P. 2000. The study of Matthayomsuksa 2 students achievement with creative thinking and achievement motivation. M.Ed. Thesis. Bangkok: Srinakharinwirot University, Thailand. Unpublished document.

9. Khondee, T. 2001. The Study of some factors influencing Matthayomsuksa 3 students' ambition. M.Ed. Thesis. Bangkok: Srinakharinwirot University, Thailand. Unpublished document.

10. Sunkamarn, M. 2004. Selected variables relating to Adversity Quotient of key stage 4 students in Nongkai province. M.Ed. Thesis Mahasarakham: Mahasarakham University, Thailand. Unpublished document.

11. McClelland, D.C. 1961. The achieving society. Princeton, NJ: Van Nostrand. ISBN: 9780029205105. 